\title{
Blood pressure and calcium intake are related to bone density in adult males
}

\author{
Jill A. Metz ${ }^{1}$, Cynthia D. Morris ${ }^{1}$, Leslie A. Roberts ${ }^{2}$, Michael R. McClung ${ }^{2}$ and David A. McCarron ${ }^{1}$ \\ ${ }^{1}$ Department of Medicine, Division of Nephrology, Hypertension and Clinical Pharmacology, \\ Oregon Health Sciences University, Portland, OR, USA \\ ${ }^{2}$ Providence Medical Center, Providence Center for Osteoporosis Research, Portland, OR, USA
}

(Received 15 June 1998 - Revised 30 November 1998 - Accepted 10 February 1999)

\begin{abstract}
Based on the premise that elevated blood pressure and low bone mass have both been associated with poor $\mathrm{Ca}$ nutriture and disturbances in $\mathrm{Ca}$ metabolism, a cross-sectional study was employed to determine if blood pressure and dietary $\mathrm{Ca}$ intake were significantly related to bone mass. Forty-seven men between 24-77 years of age with blood pressure values ranging from normal to mildly elevated comprised the study group. Blood pressure was measured with a random-zero sphygmomanometer. Bone mineral content (BMC) and density (BMD) of the hip, spine and total body were measured with dual-photon absorptiometry. Dietary intake and physical activity were also assessed. Multiple linear regression analysis was used for statistical analysis. After adjusting for known confounding variables (age, BMI, Ca intake, and others) diastolic blood pressure was negatively related to $\mathrm{BMC}(P \leq 0.05)$ and $\mathrm{BMD}(P \leq 0.01)$ of the total body, trochanteric region $(P<0.01)$ and Ward's triangle $(P<0.05)$, and to BMC of the femoral neck $(P<0.05)$ and lumbar spine, although the latter was just shy of statistical significance $(P=0 \cdot 058)$. Systolic blood pressure was negatively related to trochanteric BMD $(P=0.04)$ and BMC $(P=0.06)$. Ca intake was positively related to total body $\mathrm{BMD}(P=0.005)$, and $\mathrm{BMC}$ of the lumbar spine $(P=0.05)$. In this population of men, $\mathrm{Ca}$ intake was a positive predictor, and blood pressure was a negative predictor of regional measures of bone mass. These findings support the concept that independent of age, BMI and $\mathrm{Ca}$ intake, elevated blood pressure varies indirectly with bone mass and density, known predictors of osteoporotic fractures. Future studies are needed to determine whether elevated blood pressure is causally related to the development of low bone mass, and what role dietary Ca plays in that pathway.
\end{abstract}

Blood pressure: Calcium intake: Bone mass

Hypertension and osteoporosis are both chronic conditions that are associated with poor Ca nutrition (National Institutes of Health, 1994; Bucher et al. 1996). Hypertensive individuals manifest a number of disturbances in $\mathrm{Ca}$ metabolism that are also consistent with a metabolic profile leading to enhanced bone resorption and subsequent bone loss. These disturbances include elevated parathyroid hormone levels, increased urinary $\mathrm{Ca}$ excretion, abnormal gut absorption of $\mathrm{Ca}$, and deficient dietary $\mathrm{Ca}$ intake (McCarron, 1989; Hamet, 1995). While rat models of hypertension exhibit excessive bone loss, abnormal bone architecture and reduced levels of bone mineral mass compared with normotensive controls (Izawa et al. 1985; Lucas et al. 1986; Metz et al. 1988, 1990; Yamori et al. 1991; Wang et al. 1993), the relationship between blood pressure and bone mineral density (BMD) in a human population has not been previously explored. The objective of the present study was to examine the relationship between blood pressure and regional measures of bone mass in a population with blood pressures ranging from normal to mildly elevated.

\section{Subjects and methods}

\section{Subjects}

The subjects for this study were participants in a clinical trial that was specifically recruiting individuals with both normal and mildly elevated blood pressure values. Informed consent was obtained from each subject, and all procedures were approved by the Institutional Review Board of the Oregon Health Sciences University. The procedures followed were in accord with the ethical standards of the responsible committee on human experimentation.

\footnotetext{
Abbreviations: BMC, bone mineral content; BMD, bone mineral density; DBP, diastolic blood pressure; SBP, systolic blood pressure. 
Forty-seven men, aged 24-77 years, with blood pressures ranging from normal to mildly elevated, participated in the study. Elevated blood pressure was defined as mean arterial pressure greater than or equal to $105 \mathrm{mmHg}$. During the run-in period blood pressure medication was withheld for a minimum of 4 weeks before randomization to treatment limbs, either active agent or placebo. Participants who had previously taken thiazide diuretics or oral or topical steroids were excluded from the study. Additional exclusion criteria included secondary hypertension of any aetiology, weight $>150 \%$ of ideal body weight according to the Metropolitan Life height and weight tables, chronic alcoholism or drug addiction, congestive heart failure, emphysema, myocardial infarction within the last year, renal disease, history of gastrectomy, hypogonadism, and any disease or concurrent medication use known to affect $\mathrm{Ca}$ balance.

\section{Procedures}

Blood pressure in the sitting position was measured with a random-zero sphygmomanometer. Blood pressure was measured after $5 \mathrm{~min}$ rest and recorded at 1 min intervals for $4 \mathrm{~min}$ with the arm at cardiac level. The average of four readings was used. BMD was measured once at the lumbar spine and proximal femur, and in the total body, with dualphoton absorptiometry using a Lunar DP4 dichromatic bone densitometer (Lunar Corporation, Madison, WI, USA) with a ${ }^{153} \mathrm{Gd}$ source. Six $24 \mathrm{~h}$ recalls were solicited over the study period. Dietary information was collected by a registered dietitian who asked participants to recall in detail their dietary intake over the previous $24 \mathrm{~h}$ period. Food models were used as prompts. Participants were not told in advance that dietary information would be solicited on specific visits. Dietary data were analysed using a licensed copy of the University of Minnesota Nutrition Coordinating Center Nutrition Data System. Current leisure-time physical activity (h/week) was estimated from questionnaire responses.

\section{Statistical analysis and model selection}

SAS $^{\odot}$ for personal computers (1987; Statistical Analysis Systems Inc., Cary, NC, USA) was used for all statistical procedures. Descriptive statistics (means, SD and ranges) were determined for all variables. Verification of normally distributed data was confirmed during the exploratory data analysis phase. Multiple linear regression analysis was used to determine if blood pressure and dietary $\mathrm{Ca}$ were significantly $(P<0.05)$ associated with regional bone mineral content (BMC) or BMD variables while adjusting for confounding variables. Each bone variable was treated as a dependent variable and all potential predictors and covariates were treated as independent variables, and were regressed $v$. the dependent variables. Independent variables selected for inclusion in the models were determined both by theoretical associations to bone mass and through strong relationships observed during exploratory data analysis. Because of the small sample size for the number of individuals with complete data ( $n$ 47), the number of variables included in each model was limited to a maximum of five. Age and BMI were used in all models because of their well-known associations with bone mass; systolic blood pressure (SBP) and diastolic blood pressure (DBP) were used separately in otherwise similar models. $\mathrm{Ca}, \mathrm{Ca}^{2}$, alcohol, and physical activity were retained in models if they contributed a reasonable level of explanatory power $(P \leq 0 \cdot 30)$. The same models were used for each regional bone site. No two independent variables were correlated above $0 \cdot 29$, with the exception of $\mathrm{Ca}$ and $\mathrm{Ca}^{2}$, which were expected to be highly correlated. A quadratic term for $\mathrm{Ca}$ intake $\left(\mathrm{Ca}^{2}\right)$ was included in model selection because of its known association with BMD as a 'threshold nutrient', i.e., the association is non-linear (Matkovic \& Heaney, 1992). Squared semi-partial (type II) correlation coefficients were determined for each independent variable in order to evaluate the relative proportion of variance that could be explained by each variable per model, while simultaneously controlling for the other independent variables in the model. The following models were used:

total body $\mathrm{BMD}$ or $\mathrm{BMC}=$ intercept $+\beta_{1}$.age $+\beta_{2}$. $\mathrm{BMI}$

$$
+\beta_{3} \cdot \mathrm{ca}+\beta_{4} \cdot \mathrm{ca}^{2}+\beta_{5} \cdot \mathrm{DBP} \text { or } \beta_{5} \cdot \mathrm{SBP}+e,
$$

trochanteric $\mathrm{BMD}$ or $\mathrm{BMC}=$ intercept $+\beta_{1}$.age $+\beta_{2}$. $\mathrm{BMI}$

$+\beta_{3}$.physical activity $+\beta_{4}$. DBP or $\beta_{4} \cdot \mathrm{SBP}+e$,

femoral neck BMD or BMC $=$ intercept $+\beta_{1}$.age

$$
+\beta_{2} \cdot \mathrm{BMI}+\beta_{3} \text {.alcohol }+\beta_{4} \cdot \mathrm{DBP} \text { or } \beta_{4} \cdot \mathrm{SBP}+e,
$$

Ward's triangle $\mathrm{BMC}$ or $\mathrm{BMD}=$ intercept $+\beta_{1}$. age

$$
+\beta_{2} \cdot \mathrm{BMI}+\beta_{3} \text {.alcohol }+\beta_{4} \cdot \mathrm{DBP} \text { or } \beta_{4} \cdot \mathrm{SBP}+e,
$$

lumbar spine (L2-4) $\mathrm{BMC}$ or $\mathrm{BMD}=$ intercept $+\beta_{1}$. age

$$
+\beta_{2} \cdot \mathrm{BMI}+\beta_{3} \cdot \mathrm{ca}+\beta_{4} \cdot \mathrm{ca}^{2} \mathrm{DBP} \text { or } \beta_{4} \cdot \mathrm{SBP}+e,
$$

where ca is $\mathrm{Ca}$ intake and $e$ is random error.

\section{Results}

Descriptive statistics for the study population are shown in Table 1.

Multivariate statistics for the association between DBP, dietary $\mathrm{Ca}$, and regional $\mathrm{BMD}$ and $\mathrm{BMC}$ are shown in Table 2 . DBP was negatively $(P \leq 0.05)$ related to BMD and BMC of the total body, trochanteric region, and Ward's triangle, and to BMC of the femoral neck. SBP was negatively related to $\operatorname{BMD}(P=0.0430)$ and just shy of statistical significance for $\mathrm{BMC}(P=0.0578)$ of the trochanteric region in comparable models, but not to the remaining bone measurements. Dietary $\mathrm{Ca}$ intake was positively $(P=0.046)$ associated and $\mathrm{Ca}^{2}$ was negatively associated $(P<0.04)$ with total body BMD and with BMC of the lumbar spine $(P<0 \cdot 05)$.

Covariates significantly $(P<0 \cdot 05)$ associated with regional bone measurements in models with DBP included age, BMI, and physical activity level. Age was negatively related to BMD of the Ward's triangle $(P=0.0034)$ and femoral neck $(P=0.0478)$. BMI was positively related to BMC and BMD of the total body, Ward's triangle $(P=0.058)$ and lumbar spine, and to trochanteric BMC $(P<0 \cdot 0485)$. Activity level was negatively associated with $\mathrm{BMD}(P=0.0297)$ and $\mathrm{BMC}(P=0.0475)$ of the trochanteric region. 
Table 1. Characteristics of the forty-seven subjects in the present study (Mean values, standard deviations and ranges)

\begin{tabular}{|c|c|c|c|}
\hline Variable & Mean & SD & Range \\
\hline Age (years) & $50 \cdot 4$ & $12 \cdot 8$ & $24-77$ \\
\hline BMI $\left(\mathrm{kg} / \mathrm{m}^{2}\right)$ & $27 \cdot 4$ & 3.7 & $22 \cdot 1-35 \cdot 0$ \\
\hline Systolic blood pressure $(\mathrm{mmHg})$ & 131.8 & 13.8 & $105.5-164.5$ \\
\hline Diastolic blood pressure $(\mathrm{mmHg})$ & $82 \cdot 7$ & $9 \cdot 3$ & $60 \cdot 0-100 \cdot 0$ \\
\hline Femoral neck BMD $\left(\mathrm{g} / \mathrm{cm}^{2}\right)$ & 1.020 & 0.167 & $0.700-1.570$ \\
\hline Femoral neck BMC (g) & $5 \cdot 715$ & $1 \cdot 176$ & $3 \cdot 200-10 \cdot 700$ \\
\hline Lumbar spine (L2-4) BMD $\left(\mathrm{g} / \mathrm{cm}^{2}\right)$ & 1.343 & 0.173 & $1.071-1.862$ \\
\hline Lumbar spine BMC (g) & 69.59 & 11.23 & $51.64-96.64$ \\
\hline Total body BMD $\left(\mathrm{g} / \mathrm{cm}^{2}\right)$ & 1.261 & 0.097 & $0.949-1.445$ \\
\hline Total body BMC (g) & 3473.96 & 456.89 & $2682.00-4732.00$ \\
\hline Trochanteric BMD $\left(\mathrm{g} / \mathrm{cm}^{2}\right)$ & 0.880 & 0.113 & $0.650-1.160$ \\
\hline Trochanteric BMC $(\mathrm{g})$ & $14 \cdot 107$ & 2.596 & $8 \cdot 220-20 \cdot 870$ \\
\hline Ward's triangle BMD $\left(\mathrm{g} / \mathrm{cm}^{2}\right)$ & 0.840 & 0.197 & $0.460-1.570$ \\
\hline Ward's triangle BMC $(\mathrm{g})$ & 2.748 & 0.953 & $1.260-7.640$ \\
\hline Leisure-time activity (h/week) & 11.8 & 9.5 & $0.0-40 \cdot 0$ \\
\hline Alcohol intake $(\mathrm{g} / \mathrm{d})$ & 14.6 & 23.5 & $0.0-91.3$ \\
\hline Energy intake (kcal/d) & 2208.8 & 508.5 & $1212 \cdot 3-3455 \cdot 8$ \\
\hline$(\mathrm{kJ} / \mathrm{d})$ & 9277.0 & 2135.7 & $5091 \cdot 7-14514 \cdot 4$ \\
\hline Protein intake $(\mathrm{g} / \mathrm{d})$ & 88.9 & 24.5 & $38.8-155.2$ \\
\hline Calcium intake (mg/d) & 865.5 & 323.7 & $317 \cdot 8-1610 \cdot 6$ \\
\hline Sodium intake (mg/d) & $2790 \cdot 7$ & $751 \cdot 1$ & $1313 \cdot 4-4930 \cdot 7$ \\
\hline Potassium intake (mg/d) & 3282.0 & $826 \cdot 3$ & $1564 \cdot 0-5223 \cdot 3$ \\
\hline Magnesium intake $(\mathrm{mg} / \mathrm{d})$ & $356 \cdot 8$ & 123.5 & $163 \cdot 4-713.0$ \\
\hline
\end{tabular}

$\mathrm{BMC}$, bone mineral content; BMD, bone mineral density.

Table 2. Squared semi-partial correlation coefficients $\left(S-P R^{2}\right)$, multiple regression coefficients $(\beta)$ and standard errors for the association between blood pressure and regional measures of bone mineral density (BMD) and bone mineral content (BMC) in men

(S-PR ${ }^{2}$ describes the amount of variation explained in the dependent variable by the predictor variable, whereas $\beta$ describes the magnitude and the direction of the association between the predictor and dependent variables)

\begin{tabular}{|c|c|c|c|c|c|c|}
\hline & \multicolumn{3}{|c|}{ BMD } & \multicolumn{3}{|c|}{ BMC } \\
\hline & S-PR ${ }^{2}$ & $\beta$ & SE & S-PR ${ }^{2}$ & $\beta$ & SE \\
\hline \multicolumn{7}{|l|}{ Total body } \\
\hline age & 0.030 & -0.0015 & 0.0009 & 0.002 & -1.83 & 5.23 \\
\hline BMI & 0.320 & $0.0162^{* *}$ & 0.0031 & 0.223 & $63 \cdot 65^{\star *}$ & $17 \cdot 37$ \\
\hline $\mathrm{Ca}$ & 0.100 & $0.0005^{\star *}$ & 0.0002 & 0.049 & $1 \cdot 71 \dagger$ & 0.995 \\
\hline $\mathrm{Ca}^{2}$ & 0.110 & $-0.0000^{\star *}$ & -0.000001 & 0.054 & $-0.0009 \dagger$ & 0.0005 \\
\hline DBP & 0.090 & $-0.0035^{\star *}$ & 0.0013 & 0.087 & $-16 \cdot 06^{\star}$ & 7.03 \\
\hline \multicolumn{7}{|l|}{ Trochanteric } \\
\hline age & 0.003 & -0.0005 & 0.0013 & 0.066 & $0.0561 \dagger$ & 0.0297 \\
\hline BMI & 0.038 & 0.0065 & 0.0046 & 0.090 & $0.2303^{*}$ & 0.1049 \\
\hline physical activity & 0.097 & $-0.004^{*}$ & 0.0018 & 0.078 & $-0.0816^{\star}$ & 0.0399 \\
\hline DBP & 0.135 & $-0.0051^{\star *}$ & 0.0019 & 0.181 & $-0.1374^{\star \star}$ & 0.0441 \\
\hline \multicolumn{7}{|l|}{ Femoral neck } \\
\hline age & 0.081 & $-0.0039^{\star}$ & 0.0019 & 0.011 & -0.0103 & 0.0142 \\
\hline BMI & 0.055 & $0.0114 \dagger$ & 0.0068 & 0.040 & 0.0694 & 0.0500 \\
\hline alcohol & 0.011 & 0.0008 & 0.0010 & 0.034 & 0.0097 & 0.0076 \\
\hline DBP & 0.044 & -0.0042 & 0.0028 & 0.092 & $-0.0433^{\star}$ & 0.0206 \\
\hline \multicolumn{7}{|l|}{ Lumbar spine } \\
\hline age & 0.033 & 0.0016 & 0.0021 & 0.019 & 0.1370 & 0.1368 \\
\hline BMI & 0.153 & $0.0190^{*}$ & 0.0071 & 0.073 & $0.8926^{*}$ & 0.4541 \\
\hline $\mathrm{Ca}$ & 0.052 & $0.0007 \dagger$ & 0.0004 & 0.077 & $0.0525^{\star}$ & 0.0260 \\
\hline $\mathrm{Ca}^{2}$ & 0.061 & $-0.000004 \dagger$ & 0.000002 & 0.091 & $0.00003^{*}$ & 0.0001 \\
\hline DBP & 0.037 & -0.0036 & 0.0029 & 0.070 & $-0.3526 \dagger$ & 0.1838 \\
\hline \multicolumn{7}{|l|}{ Ward's triangle } \\
\hline age & 0.158 & $-0.0065^{\star *}$ & 0.002 & 0.018 & -0.0107 & 0.0113 \\
\hline BMI & 0.052 & $0.0130 \dagger$ & 0.0072 & 0.076 & $0.0771^{*}$ & 0.0395 \\
\hline alcohol & 0.019 & 0.0012 & 0.0011 & 0.035 & 0.0080 & 0.0060 \\
\hline DBP & 0.069 & $-0.0062^{*}$ & 0.0030 & 0.090 & $-0.0346^{*}$ & 0.0162 \\
\hline
\end{tabular}

DBP, diastolic blood pressure.

${ }^{\star} P<0.05,{ }^{\star *} P<0.005, \dagger P \leq 0.10$. 
Covariates significantly associated with regional bone measurements in models with SBP included age, BMI, and $\mathrm{Ca}$ intake. Consistent with models that included DBP, age was negatively related to BMD of the Ward's triangle $(P=0.0044)$ and femoral neck $(P=0 \cdot 0546)$. BMI was positively related to BMC and BMD of the total body $(P \leq 0.004)$ and to BMD of the lumbar spine $(P=0.02)$. $\mathrm{Ca}$ intake was positively associated $(P=0.0058)$ and $\mathrm{Ca}^{2}$ was negatively associated $(P=0.0074)$ with total body BMD.

Squared semi-partial correlations are also shown in Table 2 . These correlation coefficients provide information on the proportion of variance each predictor variable is able to explain in each of the bone mass variables. Depending on the model, DBP explained between 4 and $18 \%$ of the variation in bone mass measurements. While not appropriate to compare these coefficients across different models, the data do suggest that within models, DBP explains as much of the variance in bone mass as do many of the other variables having a known and significant association with bone mass.

\section{Discussion}

The purpose of the present study was to determine the nature of the relationship between blood pressure, dietary $\mathrm{Ca}$ and total body and regional measures of bone mass in a male population with normal to mildly elevated blood pressures. The rationale was based on the premise that a subset of individuals with hypertension manifest a disturbed $\mathrm{Ca}$ metabolic profile compatible with consequent loss of bone tissue, a postulate supported by the consistent observation of low BMD or BMC in a number of experimental models of hypertension (Izawa et al. 1985; Lucas et al. 1986; Metz et al. 1988, 1990; Yamori et al. 1991; Wang et al. 1993). Our findings show that DBP was independently and negatively related to BMD and BMC of the total body and to regional measures of BMD and BMC. SBP was found to be significantly and negatively related to trochanteric BMD, and the association was just shy of statistical significance for BMC.

The observational nature of this study precludes identifying any causal associations between blood pressure and bone mass measurements, i.e. that high blood pressure contributes to bone loss. However, these preliminary findings are indirectly supported by experimental data demonstrating that indices of bone mineral metabolism associated with the metabolic sequelae related to bone loss are also manifest in some individuals with hypertension (Resnick et al. 1983; Strazzulo et al. 1983; Grobbee et al. 1986; McCarron, 1989; Papagalanis et al. 1991; Young et al. 1992; Hamet, 1995). The most relevant of these disturbances include lower dietary $\mathrm{Ca}$ intake, inappropriately lower intestinal absorption of $\mathrm{Ca}$, and increased urinary $\mathrm{Ca}$ excretion in the setting of higher circulating parathyroid hormone levels, lower vitamin $\mathrm{D}_{3}$ concentrations, and reductions in plasma ionized $\mathrm{Ca}$. When dietary $\mathrm{Ca}$ intake is sufficient, it may act to lower blood pressure by a direct effect on vascular smooth muscle cells such that the cell's ability to extrude $\mathrm{Ca}$ is improved. Similarly, the Ca-regulating hormones have vasoactive properties that could have an indirect impact on the same cellular functions. Dietary Ca may also affect blood pressure by altering sympathetic nervous system activity, by modifying the metabolism of other electrolytes such as $\mathrm{Na}$ or K, or by affecting the central nervous system (Hatton \& McCarron, 1994). Although these endpoints were not measured in the present study, the consistency of these metabolic defects observed in previous studies of human essential hypertension is remarkable (Resnick et al. 1983; Strazzulo et al. 1983; Grobbee et al. 1986; McCarron, 1989; Papagalanis et al. 1991; Young et al. 1992; Hamet, 1995).

An additional line of evidence in support of the present findings comes from rat models of hypertension in which bone mass has been shown to be reduced or metabolically altered compared with normotensive controls (Izawa et al. 1985; Lucas et al. 1986; Metz et al. 1988, 1990; Yamori et al. 1991; Wang et al. 1993). In addition, human renal stone disease is associated with increased $\mathrm{Ca}$ excretion, hypertension, reduced dietary $\mathrm{Ca}$ intake and reduced levels of bone mass (Tibblin, 1967; Cirillo \& Laurenzi, 1988; Cappuccio et al. 1990; Bataille et al. 1991; Curhan et al. 1993; Jaeger et al. 1994). MacGregor \& Cappuccio (1993) have also hypothesized that these abnormalities in $\mathrm{Ca}$ metabolism in patients with hypertension may contribute to long-term bone demineralization.

Why DBP was a better predictor of bone mass than SBP is uncertain. This finding may reflect the fact that DBP is more dependent on volume status than SBP. Volume-dependent variations, i.e. salt sensitivity, in blood pressure have been shown to be more sensitive to modifications in dietary $\mathrm{Ca}$ intake and/or markers of perturbed Ca metabolism compared with volume-resistant blood pressure variations (Yamakawa et al. 1992; Weinberger et al. 1993). Thus, it follows that total body and regional BMD, an overall marker of Ca status, would be more closely related to DBP than SBP. However, volume-dependent variations in blood pressure regulation were not assessed in the present study.

Covariates significantly related to bone measurements included $\mathrm{Ca}, \mathrm{Ca}^{2}$, BMI, age, and activity level. Of these, variables negatively related to bone measurements included age, $\mathrm{Ca}^{2}$ and activity level. Results for the negative association between age and bone measurements are consistent with the literature indicating that BMD in general declines with age (Garn et al. 1967; Hernandez-Avila et al. 1991). Additionally, the negative quadratic term for $\mathrm{Ca}$ $\left(\mathrm{Ca}^{2}\right)$ indicates that overall, the positive association observed between $\mathrm{Ca}$ and total body BMD in this model is non-linear, and that $\mathrm{Ca}$ consumption beyond a defined level may offer no additional benefit to BMD. This is consistent with a 'threshold effect' of $\mathrm{Ca}$ on BMD which has been previously demonstrated (Heaney, 1992; Matkovic \& Heaney, 1992). The negative relationship observed between activity level and trochanteric BMD and BMC seems counterintuitive, but may be a result of life-long exposure of an excessive weight-bearing load received directly to the trochanter.

The positive association between BMI and selected bone measurements is consistent with the well-established notion that BMI is a positive determinant of BMD (Felson et al. 1993). While the positive relationship observed in the present study between $\mathrm{Ca}$ intake and total body BMD is 
consistent with other studies in women and children (Dawson-Hughes et al. 1990; Chapuy et al. 1992; Johnston et al. 1992; Recker et al. 1992; Lloyd et al. 1993; Reid et al. 1993), the relationship between Ca intake and BMD in men is relatively unexplored and these findings are supportive of the limited literature available on $\mathrm{Ca}$ and bone health in men (Cooper et al. 1988; Holbrook et al. 1988; Kelly et al. 1990; Orwoll et al. 1990).

The present study has several limitations. The study design prevents making causal inferences, and the results cannot be generalized to other populations. In addition, the sample size was small, and some of the control variables were assessed by recall (diet, physical activity), and may lack a high degree of precision as a result. In addition, the method used to measure bone mass, dual-photon absorptiometry, offers less precision than its more contemporary counterpart, dual-energy X-ray absorptiometry (Lees \& Stevenson, 1992), particularly in patients with increasing body mass (Martin et al. 1993), however, this method still offers high accuracy and adequate clinical precision (Mazess \& Barden, 1988). Because these biases would serve to increase variability and misclassification bias, the effect would be a dilutional one; to bias the results in the direction of the null hypothesis. As a consequence, it is possible that the results found in this study are conservative estimates of the strength of the relationships observed. Considering these limitations, and that the hypotheses tested were biologically plausible, the fact that significant results were found suggests the possibility that the relationship between higher blood pressure and reduced bone mass may not be entirely accounted for by other known risk factors. However, a larger sample size in addition to the measurement of biochemical indices of bone mineral metabolism would need to be employed to assess more carefully the relationship between increased arterial pressure and BMD. In fact, it is possible that increases in blood pressure and reductions in BMD are independent pathophysiological expressions of reduced $\mathrm{Ca}$ intake, and/or one or more abnormalities of $\mathrm{Ca}$ metabolism. Thus, to the authors' knowledge, these data provide the first observation in human subjects, that blood pressure and bone mass are inversely related; further work is needed to confirm these findings, and to explore the nature of this relationship.

\section{Acknowledgements}

This study was supported in part by the National Dairy Council, National Dairy Promotion and Research Board, and the Clinical Nutrition Research Unit, NIDDK (AHR-2) 5 P30 DK40566.

\section{References}

Bataille P, Achard JM, Fournier A, Boudailliez B, Westeel PF, Esper N, Bergot C, Jans I, Lalau JD, Petit J, Henon G, Jeantet MAL, Bouillon R \& Sebert JL (1991) Diet, vitamin D and vertebral mineral density in hypercalciuric calcium stone formers. Kidney International 39, 1193-1205.

Bucher HC, Cook RJ, Guyatt GH, Lang JD, Cook DJ, Hatala R \& Hunt DL (1996) Effects of dietary calcium supplementation on blood pressure. A meta-analysis of randomized controlled trials. Journal of the American Medical Association 275, 1016-1022.
Cappuccio FP, Strazzullo P \& Mancini M (1990) Kidney stones and hypertension: population based study of an independent clinical association. British Medical Journal 300, 1234-1236.

Chapuy MC, Arlot ME, Duboeuf F, Brun J, Crouzet B, Arnaud S, Delmas PD \& Meunier PJ (1992) Vitamin $\mathrm{D}_{3}$ and calcium to prevent hip fractures in elderly women. New England Journal of Medicine 327, 1637-1642.

Cirillo M \& Laurenzi M (1988) Elevated blood pressure and positive history of kidney stones: results from a populationbased study. Journal of Hypertension 6, Suppl. 4, S485-S486.

Cooper C, Barker JDP \& Wickham C (1988) Physical activity, muscle strength and calcium intake in fracture of the proximal femur. British Medical Journal 297, 1443-1446.

Curhan GC, Willett WC, Rimm EB \& Stampfer MJ (1993) A prospective study of dietary calcium and other nutrients and the risk of symptomatic kidney stones. New England Journal of Medicine 328, 833-838.

Dawson-Hughes B, Dallal GE, Krall EA, Sadowski L, Sahyoun N \& Tannenbaum S (1990) A controlled trial of the effect of calcium supplementation on bone density in postmenopausal women. New England Journal of Medicine 328, 878-883.

Felson DT, Zhang Y, Hannan MT \& Anderson JJ (1993) Effects of weight and body mass index on bone mineral density in men and women: The Framingham Study. Journal of Bone and Mineral Research 8, 567-573.

Garn SM, Rohmann CG \& Wagner B (1967) Bone loss as a general phenomenon in man. Federation Proceedings 26, 1729-1736.

Grobbee DE, Hackeng WHL, Birkenhager JC \& Hofman A (1986) Intact parathyroid hormone (I-84) in primary hypertension. Clinical and Experimental Hypertension, Part A, Theory and Practice 8, 299-308.

Hamet P (1985) The evaluation of the scientific evidence for a relationship between calcium and hypertension. Journal of Nutrition 125, 311s-400s.

Hatton DC \& McCarron DA (1994) Dietary calcium and blood pressure in experimental models of hypertension. Hypertension 23, 513-530.

Heaney RP (1992) Calcium intake and bone health in the adult. Clinical and Applied Nutrition 2, 10-29.

Hernandez-Avila M, Colditz GA, Stampfer MJ, Rosner B, Speizer FE \& Willett WC (1991) Caffeine, moderate alcohol intake, and risk of fractures of the hip and forearm in middle-aged women. American Journal of Clinical Nutrition 54, 157-163.

Holbrook TL, Barrett-Connor E \& Wingard DL (1988) Dietary calcium intake and risk of hip fracture: 14-year prospective population study. Lancet 2, 1046-1049.

Izawa Y, Sagara K, Kadota T \& Makita T (1985) Bone disorders in spontaneously hypertensive rat. Calcified Tissue International 37, 605-607.

Jaeger P, Lippuner K, Casez J-P, Hess B, Ackermann D \& Hug C (1994) Low bone mass in idiopathic renal stone formers: magnitude and significance. Journal of Bone and Mineral Research 9, 1525-1532.

Johnston CC, Miller JZ, Slemenda CW, Reister TK, Hui S, Christian JC \& Peacock M (1992) Calcium supplementation and increases in bone mineral density in children. New England Journal of Medicine 327, 82-87.

Kelly PJ, Pocock NA, Sambrook PN \& Eisman JA (1990) Dietary calcium, sex hormones, and bone mineral density in men. British Medical Journal 300, 1361-1364.

Lees B \& Stevenson JC (1992) An evaluation of dual-energy $\mathrm{X}$-ray absorptiometry and comparison with dual-photon absorptiometry. Osteoporosis International 2, 146-152.

Lloyd T, Andon MB, Rollings N, Martel JK, Landis JR, Demers LM, Eggli DF, Kieselhorst K \& Kulin HE (1993) Calcium supplementation and bone mineral density in adolescent girls. Journal of the American Medical Association 270, 841-844. 
Lucas PA, Brown RC, Drüeke T, Lacour B, Metz JA \& McCarron DA (1986) Abnormal vitamin D metabolism, intestinal calcium transport, and bone calcium status in the spontaneously hypertensive rat compared with its genetic control. Journal of Clinical Investigation 78, 221-227.

McCarron DA (1989) Calcium metabolism and hypertension. Kidney International 35, 717-736.

MacGreggor GA \& Cappuccio FP (1993) Hypothesis. The kidney and essential hypertension: a link to osteoporosis? Journal of Hypertension 11, 781-785.

Martin P, Verhas M, Als C, Geerts L, Paternot J \& Bergmann P (1993) Influence of patient's weight on dual-photon absorptiometry and dual-energy X-ray absorptiometry measurements of bone mineral density. Osteoporosis International 3, 198-203.

Matkovic V \& Heaney RP (1992) Calcium balance during human growth: evidence for threshold behavior. American Journal of Clinical Nutrition 55, 992-996.

Mazess RB \& Barden HS (1988) Measurement of bone by dual-photon absorptiometry (DPA) and dual-energy X-ray absorptiometry (DEXA). Annales Chirurgiae et Gynaecologiae 77, 197-203.

Metz JA, Karanja N \& McCarron DA (1988) Bone density comparison in two hypertensive strains: effects of dietary sodium. Clinical Research 36, 139A.

Metz JA, Karanja N, Young EW, Morris CD \& McCarron DA (1990) Bone mineral density in spontaneous hypertension: differential effects of dietary calcium and sodium. American Journal of Medical Science 300, 225-230.

National Institutes of Health (1994) Optimal Calcium Intake. NIH Consensus Statement no. 12, part 4, pp.1-31. Bethesda, MD: NIH.

Orwoll ES, Oviatt SK, McClung MR, Deftos LJ \& Sexton G (1990) The rate of bone mineral loss in normal men and the effects of calcium and cholecalciferol supplementation. Annals of Internal Medicine 112, 29-34.

Papagalanis ND, Skopelitis P, Kourti A, Kostogianni G, Karabatsos A, Gennadiou M, Thomas S, Samartzis M \& Mountokalakis T (1991) Urine calcium excretion, nephrogenous cyclic-adenosine monophosphate and serum parathyroid hormone levels in patients with essential hypertension. Nephron 59, 226-231.

Recker RR, Davies KM, Hinders SM, Heaney RP, Stegman MR \& Kimmel DB (1992) Bone gain in young adult women. Journal of the American Medical Association 268, 2403-2408.

Reid IR, Ames RW, Evans MC, Gamble GD \& Sharpe SJ (1993) Effect of calcium supplementation on bone loss in postmenopausal women. New England Journal of Medicine 328, 460-464.

Resnick LM, Laragh JH, Sealey JE \& Alderman MH (1983) Divalent cations in essential hypertension: relations between serum ionized calcium, magnesium and plasma renin activity. New England Journal of Medicine 309, 888-891.

Strazzulo P, Nunziata P, Cirillo M, Giannattasio R, Ferrara LA, Mattioli PL \& Mancini M (1983) Abnormalities of calcium metabolism in essential hypertension. Clinical Science $\mathbf{6 5}$, 137-141.

Tibblin G (1967) High blood pressure in men aged 50: a population study of men born in 1913. Acta Medica Scandinavica 470, Suppl. 1, 1-84.

Wang TM, Hsu JF, Lee WSS \& Matthews JL (1993) Evidence for reduced cancellous bone mass in the spontaneously hypertensive rat. Bone and Mineral 20, 251-264.

Weinberger MH, Wagner UL \& Fineberg NS (1993) The blood pressure effects of calcium supplementation in humans of known responsiveness. American Journal of Hypertension 6, 799-805.

Yamakawa H, Suzuki H, Nakamura M, Ohno Y \& Saruta T (1992) Disturbed calcium metabolism in offspring of hypertensive parents. Hypertension 19, 528-534.

Yamori Y, Fukuda S, Tsuchikura S, Ikeda K, Nara Y \& Horie R (1991) Stroke-prone SHR (SHRSP) as a model for osteoporosis. Clinical and Experimental Hypertension, Part A, Theory and Practice 13, 755-762.

Young EW, Morris CD \& McCarron DA (1992) Urinary calcium excretion in essential hypertension. Journal of Laboratory and Clinical Medicine 120, 624-632. 